\title{
Mechanistic studies of the solvolysis of alkanesulfonyl and arenesulfonyl halides
}

Malcolm J. D'Souza ${ }^{* 1}$ and Dennis N. Kevill ${ }^{2}$

\author{
Review \\ Address: \\ ${ }^{1}$ Delaware Environmental Institute, University of Delaware, 221 \\ Academy Street, Newark, Delaware 19716-5804, USA and \\ 2Department of Chemistry and Biochemistry, Northern Illinois \\ University, DeKalb, Illinois 60115-2862, USA \\ Email: \\ Malcolm J. D'Souza* - dsouza@udel.edu \\ * Corresponding author \\ Keywords: \\ correlation; Grunwald-Winstein equation; Hammett equation; \\ mechanism; solvolysis; sulfonyl halides
}

\section{Abstract}

There have been several studies on the solvolysis mechanisms for alkanesulfonyl chlorides $\left(\mathrm{RSO}_{2} \mathrm{Cl}\right)$ and arenesulfonyl chlorides $\left(\mathrm{ArSO}_{2} \mathrm{Cl}\right)$. The earlier of these studies were reviewed a little over thirty years ago by Gordon, Maskill and Ruasse (Chem. Soc. Rev. 1989, 18, 123-151) in a contribution entitled "Sulfonyl Transfer Reactions". The present review will emphasize more recent contributions and, in particular, the application of the extended Grunwald-Winstein equation and kinetic solvent isotope effects to the solvolysis reactions. There is also an appreciable number of reports concerning the corresponding anhydrides with the chloride leaving group replaced by the appropriate sulfonate leaving group, concerning sulfamoyl chlorides $\left(\mathrm{ZZ}^{\prime} \mathrm{NSO}_{2} \mathrm{Cl}\right)$ with $\mathrm{Z}$ and $\mathrm{Z}^{\prime}$ being alkyl or aryl and concerning the solvolysis of chlorosulfate esters (alkoxy- or aryloxysulfonyl chlorides), with the structures $\mathrm{ROSO}_{2} \mathrm{Cl}$ or $\mathrm{ArOSO}_{2} \mathrm{Cl}$. The solvolyses of these additional types of sulfur(VI) substrates will be the topics of a future review.

\section{Review}

\section{Introduction to solvolyses of sulfonyl} halides

In medicinal chemistry, sulfonyl chlorides are good building blocks to intermediates and complex scaffolds of sulfonamides. Gordon, Maskill, and Ruasse [1] have reviewed "Sulfonyl Transfer Reactions" in a broader sense than the coverage of the present contributions. In particular, an appreciable amount of

\author{
Beilstein J. Org. Chem. 2022, 18, 120-132. \\ https://doi.org/10.3762/bjoc.18.13 \\ Received: 11 August 2021 \\ Accepted: 01 December 2021 \\ Published: 17 January 2022 \\ Associate Editor: J. A. Murphy \\ (C) 2022 D'Souza and Kevill; licensee Beilstein-Institut. \\ License and terms: see end of document.
}


trate on reactions believed to involve a direct interaction with the substrate, or with a species (such as a cation) directly formed from the substrate.

Sulfonyl chlorides were included in several early considerations of the reaction rates, for processes involving organic substrates, as a function of solvent composition. In a very early 1927 study [4] of the solvolyses of benzenesulfonyl chloride $\left(\mathrm{C}_{6} \mathrm{H}_{5} \mathrm{SO}_{2} \mathrm{Cl}\right)$ and its $p$-methyl and $m$-nitro derivatives, solvolyzing in $50 \%$ acetone $/ 50 \%$ water $(\mathrm{v} / \mathrm{v})$ at $25.0{ }^{\circ} \mathrm{C}$, it was found that the differences in specific rates were quite small, at $0.0106 \mathrm{~min}^{-1}$ for the $p$-methyl derivative, $0.0146 \mathrm{~min}^{-1}$ for the parent compound, and $0.044 \mathrm{~min}^{-1}$ for the $m-\mathrm{NO}_{2}$ derivative. A change of solvent to $47.5 \%$ ethanol $/ 52.5 \%$ water led to very similar behavior with the corresponding specific rates being $0.0287,0.0313$, and $0.058 \mathrm{~min}^{-1}$. In modern terminology, this would suggest a close to synchronous bond-making and bondbreaking, with a small negative charge development on the sulfur at the transition state, for the solvolytic process.

Subsequent to this 1927 study, Hammett reported [5,6] in 1937 , the development of the Hammett equation, involving the consideration of a scale logarithmically related to the measured acidities for the parent benzoic acid and for a series of para and meta-substituted derivatives for a solution in water at $25.0{ }^{\circ} \mathrm{C}$. In this initial study, ortho-substituents were avoided due to the possibility of steric interactions superimposed on the inductive ones.

The Hammett substituent values obtained can be applied to the solvolyses and other reactions of substrates varying only in the aromatic ring substituent that they carry, under otherwise identical conditions as regards solvent and temperature. Frequently, as in the reactions to be reviewed in this subsection of the review, the study is of solvolysis mechanisms and the reactions involve the solvolyses of a series of para and meta-ring-substituted substrates. Applying the Hammett equation to the rate measurements of Berger and Oliver [4], we arrive, in 50\% water $/ 50 \%$ acetone $(\mathrm{v} / \mathrm{v})$ at a reaction constant $\rho$ value of +0.82 for the para-methyl derivative and of +0.71 for the meta-nitro derivative. and, for the study in $47.5 \%$ ethanol $/ 52.5 \%$ water the corresponding values are +0.22 and +0.38 , respectively. These small reaction constant $\rho$ values depend only on the type of reaction but not on the substituent used, and are consistent with the proposed bimolecular character with a considerable balance between bond formation and bond breaking.

Hedlund [7] studied the rates of solvolysis for several alkanesulfonyl chlorides in $100 \%$ water. He found lower rates of solvolysis than those for the previously studied [4] arenesulfonyl chlorides. Böhme and Schurhoff [8] similarly found that the solvolyses, in several homogeneous mixtures of an ether and water, were relatively slow. They found that the overall reaction rate could be considerably increased by the addition of reasonably powerful anionic nucleophiles. Indeed, Swain and Scott showed [9] that in $50 \%$ acetone $/ 50 \%$ water at $0.5{ }^{\circ} \mathrm{C}$, a hydroxide ion was about $10^{6}$ times more reactive than a water molecule towards benzenesulfonyl chloride. Also, for the same solvent, at $25.0^{\circ} \mathrm{C}$, they found [10] that the fluoride, with a considerably stronger carbon-halogen bond, reacted at least four orders of magnitude slower than the chloride as regards the solvolytic replacement of the halogen present in the benzenesulfonyl halide. For the reactions of the fluoride in $20 \%$ dioxane at $91{ }^{\circ} \mathrm{C}$, the $m$-nitro derivative was shown to be subject to a strong nucleophilic catalysis by acetate ion [11]. Hall [12] extended the studies of the hydrolyses of sulfonyl chlorides to sulfamoyl chlorides $\left(\mathrm{ZZ}^{\prime} \mathrm{NSO}_{2} \mathrm{Cl}\right.$, with $\mathrm{Z}$ and $\mathrm{Z}$ ' each either alkyl or aryl) and to alkoxy (or aryloxy) sulfonyl chlorides $\mathrm{ROSO}_{2} \mathrm{Cl}$ or $\mathrm{ArOSO}_{2} \mathrm{Cl}$, also named as alkyl (or aryl) chlorosulfates. These two classes of substrates will be considered in a subsequent review which will expand the coverage of the present one. It might be mentioned that Hall's claim of an $\mathrm{S}_{\mathrm{N}} 1$ pathway for some of the solvolyses of dimethylsulfamoyl chloride has been rendered unlikely by more recent studies.

Tommila and Hirsjärvi [13] found that, in water as solvent, both electron-supplying and electron-withdrawing substituents decreased the rate of the hydrolysis of benzenesulfonyl chloride. They proposed, consistent with the claim by Hall [12], that with electron-supplying substituents the reaction proceeded, in part, by an ionization $\left(S_{N} 1\right)$ mechanism. Similarly, Vizgert [14] studied the hydrolyses of the parent benzenesulfonyl chloride and a series of substituted derivatives in $70 \%$ dioxane $/ 30 \%$ water. A modest increase in rate was observed for the 2,4dimethyl derivative which then increased dramatically on going to the 2,4,6-trimethyl derivative. It was proposed that these observations constituted good evidence for the incursion of an $S_{N} 1$ pathway. A subsequent study by Vizgert and Savchuk [15] concentrated on the effect of gradually increasing the polarity of the solvent on going from $70 \%$ dioxane to $100 \% \mathrm{H}_{2} \mathrm{O}$. It was proposed that the rate changes observed as the water content increased were consistent with an $\mathrm{S}_{\mathrm{N}} 2$ reaction becoming a mixed $\mathrm{S}_{\mathrm{N}} 2-\mathrm{S}_{\mathrm{N}} 1$ situation and then, eventually, an essentially $\mathrm{S}_{\mathrm{N}} 1$ pathway was followed. It was concluded that nucleophilic attack at sulfur has many of the characteristics of attack at carbon, including the interplay of $\mathrm{S}_{\mathrm{N}} 1$ and $\mathrm{S}_{\mathrm{N}} 2$ pathways for attack at a saturated carbon atom being carried over to attack at sulfur(VI). From the experiments reported by Vizgert and Savchuk [15], we will choose just one of the many possibilities for an application of the Hammett equation [5,6]. Applying to the rate data in $30 \%$ dioxane $/ 70 \%$ water at $20{ }^{\circ} \mathrm{C}$, we can, for the parent benzenesulfonyl chloride and for the $p$-methyl and 
$p$-nitro derivatives, abstract the specific rate data from Table 1 of the publication. The Hammett treatment using appropriate substituent constants leads to a Hammett $\rho$ value of +0.35 with the $p$-methyl group present and to a very similar value of +0.37 in the presence of a $p$-nitro group. Again, these low $\rho$ values are consistent with a transition state with very similar amounts of bond-breaking and bond-making, such that only a small amount of charge develops at the $\alpha$-carbon.

Over an eleven-year period (1961-1971), Hambly and co-workers, published a series of eight papers (Solvolysis of Sulfonyl Halides, Parts I through VIII) [16-23]. In the initial study $[16,17]$ of the solvolysis of the parent benzenesulfonyl chloride and the $p$-methyl, $p$-bromo-, and $p$-nitro derivatives in aqueous dioxane, aqueous acetone, methanol/acetone, and ethanol/acetone, the $p-\mathrm{NO}_{2}$ (strongest electron-withdrawing influence) was always reacting faster than the parent and the other two derivatives and the overall behavior in a Hammett equation treatment indicated that all were reacting by an $\mathrm{S}_{\mathrm{N}} 2$ pathway. The plots all deviated modestly from linearity but overall an $\mathrm{S}_{\mathrm{N}} 2$ pathway with some degree of variation between the structures at the transition state was a logical assessment of the mechanistic situation. In a following publication [20], the solvolytic behaviors of methane- and ethanesulfonyl chlorides in the aqueous acetone and aqueous dioxane mixtures were reported. The evidence was again considered to be in favor of an $\mathrm{S}_{\mathrm{N}} 2$ pathway and the $\mathrm{S}_{\mathrm{N}} 1$ pathway, previously proposed [1315] for reactions of sulfonyl chlorides in aqueous dioxane, was not supported by the Foon and Hambly data.

When the specific rates of solvolysis of ethanesulfonyl bromide and chloride, in aqueous dioxane at $25.0^{\circ} \mathrm{C}$, are compared as regards their variation with solvent composition [19], it is found that $k_{\mathrm{Br}} / k_{\mathrm{Cl}}$ values of modest magnitude fall from 10.9 for a mole fraction of water of 0.205 to a value of 2.8 at a mole fraction of water of 0.990 . If the reactions were $S_{N} 1$ in character with a larger proportion of water in the water/dioxane mixtures, the values would be expected to decrease appreciably because of the stronger solvation by water of a developing chloride ion than of a developing bromide ion [24]. For $S_{N} 1$ reactions, $k_{\mathrm{Br}} / k_{\mathrm{Cl}}$ ratios are usually in the region of 40 [24] and much smaller values, similar to the ones of this study, are considered to reflect $\mathrm{S}_{\mathrm{N}} 2$ character.

Solvent isotope effect values $\left(k_{\mathrm{H} 2 \mathrm{O}} / k_{\mathrm{D} 2 \mathrm{O}}\right)$ for the solvolyses of methanesulfonyl chloride have been determined [20]. The value for the ratio decreased slightly with increase in temperature, from a value of 1.7 at $0{ }^{\circ} \mathrm{C}$ to 1.5 at $50{ }^{\circ} \mathrm{C}$. When the $\mathrm{H}_{2} \mathrm{O}$ and $\mathrm{D}_{2} \mathrm{O}$ are diluted with gradually increasing amounts of dioxane, there are only very small changes in the solvent isotope effect ratio. The individual specific rates of solvolysis increase by a factor of 2.3 when the pressure is raised to 2000 atmospheres but the solvent isotope effect ratio is essentially unchanged [21].

The parent benzenesulfonyl chloride and a series of monosubstituted derivatives ( $p$-nitro, $m$-nitro, $p$-bromo, $p$-methoxy, and $p$-methyl) have had their specific rates of hydrolysis measured in aqueous dioxane [22]. The observations concerning the specific rates were consistent with an $\mathrm{S}_{\mathrm{N}} 2$ pathway for the displacement of the chloride ion from the sulfur. However, for the trisubstituted 2,4,6-trimethylbenzenesulfonyl chloride, the $\mathrm{S}_{\mathrm{N}} 2$ mechanism does not give a simple rationale for the high specific rate of solvolysis observed and a partial changeover to an $\mathrm{S}_{\mathrm{N}} 1$ pathway was proposed. Vizgert [14,15] had previously suggested that the favored pathway for the hydrolysis of this substrate was by an $\mathrm{S}_{\mathrm{N}} 1$ ionization mechanism [25]. This proposal was based on the lack of acceleration in aqueous dioxane when hydroxide ion was added. As the polarity of the medium is increased, so also is the solvent ionizing power $(Y)$ and the ionization pathway could become of increasing importance and eventually dominant.

Forbes and Maskill, first in a communication [26] and then later in a full-length paper with contributions from their co-workers [27], realized that if the unimolecular reaction was occurring in aqueous dioxane solvents, then it should become even more dominant when the dioxane was replaced by 2,2,2-trifluoroethanol (TFE). Charge density distributions for TFE show a component with decreased electron density at the oxygen, which is relayed to give increased acidity for the hydrogen of the $\mathrm{OH}$ group and increased electrophilicity (solvent ionizing power) for a solvent in which it is a major component. Maskill and co-workers [26,27] investigated the solvolyses of 2,4dimethoxybenzenesulfonyl chloride and of the 2,4,6-trimethylbenzenesulfonyl chloride in $50 \% \mathrm{TFE} / 50 \%$ water $(50 \% \mathrm{TFE})$ and in the highly ionizing $97 \%$ TFE. They found no evidence for an unusually rapid reaction in these solvents and very negative entropies of activation (consistent with a bimolecular process). If in these highly ionizing solvents no changeover from an $S_{N} 2$ to an $S_{N} 1$ process is observed, then it certainly would not be expected under the much milder conditions of aqueous dioxane solvents [26,27].

It would, in turn, be worthwhile to attempt to repeat these experiments with the TFE replaced by the even more electrophilic 1,1,1,3,3,3-hexafluoro-2-propanol (HFIP) component. The 97\% TFE has a $Y_{\mathrm{Cl}}$ value (for interaction at chlorine) of 2.83, which increases to 5.08 on going to $97 \%$ HFIP [25], corresponding to a considerable increase in its ability to interact with, and assist in the removal of (as chloride ion), a chlorine attached to a carbon. 
Robertson and co-workers devised a system for a very accurate determination of rates of reaction by following changes in conductivity, with very precise temperature control. In this way, it was possible to observe systematic deviations from linearity in Arrhenius plots, which with conventional kinetic studies would be masked by a larger random scatter within the different determinations. A precise detailed treatment allowed the "second-order" heat capacities of activation $\left(\Delta C_{p}{ }^{\#}\right)$ to be determined for, among many other substrates, methane and benzenesulfonyl chlorides [28]. The magnitude of the $\Delta C_{p}{ }^{\#}$ was initially considered to be the most sensitive indicator of the extent of solvent reorganization during the substitution process. Similarly, a very accurate determination of the kinetic solvent isotope effect $\left(k_{\text {sie }}\right)$ for solvolysis in $\mathrm{H}_{2} \mathrm{O}$ or $\mathrm{D}_{2} \mathrm{O}$ based on very accurate specific rate measurements was possible. The $k_{\text {sie }}$ for the hydrolysis of alkyl chlorides is usually in the range of 1.20 to 1.25 which, at $20{ }^{\circ} \mathrm{C}$, increases to values of $1.568 \pm 0.006$ and $1.564 \pm 0.006$ for methanesulfonyl chloride and benzenesulfonyl chloride [28]. This was considered to indicate more bond breaking at the transition state for the departure of the chloride ion in the hydrolyses of the sulfonyl chlorides.

The sulfonyl halides are not ideal substrates for studies of this type since they range from poorly soluble to almost insoluble in water. The parent compounds distinguished strongly between reactions with a water molecule and added hydroxide ion. The selectivity ratio [10], $k_{\mathrm{OH}^{-}} / k_{\mathrm{H} 2 \mathrm{O}}$ with benzenesulfonyl chloride as the substrate having a value of $7 \times 10^{8}$, considerably larger than the value of $10^{3}$ for primary alkyl halides $[4,16,17]$ and consistent with an $\mathrm{S}_{\mathrm{N}} 2$ pathway. Introduction of methyl groups onto the aromatic ring considerably reduced the selectivity ratio, with specific rate values [14] of $1.66 \times 10^{-4} \mathrm{~s}^{-1}$ in $100 \%$ $\mathrm{H}_{2} \mathrm{O}$ increasing only to $1.73 \times 10^{-4} \mathrm{~s}^{-1}$ in the presence of $0.004 \mathrm{M}$ potassium hydroxide. The only small difference between the specific rates of reaction with solvent water and the overall value with added hydroxide ion suggested [14], but does not demand, a unimolecular $\mathrm{S}_{\mathrm{N}} 1$ pathway [28]. Overall, it was concluded [28] that the hydrolyses of both the methane- and benzenesulfonyl chlorides usually involve an $\mathrm{S}_{\mathrm{N}} 2$ pathway.

In a subsequent paper [29], for the solvolyses of benzenesulfonyl chloride and its $p-\mathrm{MeO}, p-\mathrm{Me}, p-\mathrm{Br}$, and $p-\mathrm{NO}_{2}$ derivatives specific rates of hydrolysis were measured in the $0{ }^{\circ} \mathrm{C}$ to $25{ }^{\circ} \mathrm{C}$ range. The thermodynamic parameters, $\Delta G^{\#}, \Delta H^{\#}$, and $\Delta S^{\#}$ and the above mentioned second-order parameter $\Delta C_{p}{ }^{\#}$ were derived. The reactions were believed to be $\mathrm{S}_{\mathrm{N}} 2$ in character and a trigonal bipyramidal transition state was proposed. Electron withdrawal led to higher values of $\Delta H^{\#}$ and less negative values of $\Delta S^{\#}$. The $\Delta C_{p}{ }^{\#}$ values correlated very well against $\Delta S^{\#}$ values, except for an unusually low value for the $p-\mathrm{MeO}$ derivative. Arguments to explain this [29] were presented at length but do not seem to be totally convincing.

In a third paper [30], kinetic solvent isotope effects ( $k_{\text {sie }}$ values) were reported as $k_{\mathrm{H} 2 \mathrm{O}} / k_{\mathrm{D} 2 \mathrm{O}}$ for the same group of benzenesulfonyl chlorides as reported on in part II [29]. Differences are found, as one might predict, in the nucleophilic processes for attack by water on sulfur rather than on carbon, indicating differences in the detailed bimolecular processes. In the paper, a scheme is presented which involves formation of an ion pair which can then either return to reactant or go on to products (Scheme 1).

$$
\mathrm{RX} \stackrel{k_{1}}{\stackrel{k_{2}}{\rightleftarrows}} \mathrm{R}^{+} \mathrm{X}^{-} \stackrel{k_{3}}{\longrightarrow} \text { products }
$$

Scheme 1: Organic reactions where the breaking of a $\mathrm{C}-\mathrm{X}$ bond involves the formation of a high energy ion-pair intermediate.

The introduction of the ion-pair return $\left(k_{2}\right)$ step might seem rather trivial but it has profound effects as regards interpretation of the thermodynamic parameters. The general assumption until this expansion of the pathway was that the specific rate $(k)$ was either about the same throughout the series of substituted compounds or it varies linearly with the $\sigma$ values of the substituents. More recently, several groups have zeroed in as regards the incorporation of Scheme 1 into the development of a new model for solvolytic reactions and it has been shown conclusively, as Robertson gracefully acknowledged, in his participation as a co-author of a chapter in "Progress in Physical Organic Chemistry" [31], that this equilibrium needs to be incorporated into treatments based on the magnitudes of the heat capacities of activation $\left(\Delta C_{p}{ }^{\#}\right)$. The need to incorporate the return from an ion pair to a covalent molecule, makes what was already a rather controversial area of reaction kinetics even more complicated and controversial. The reader wanting more detail is referred to the above mentioned comprehensive review entitled "Solvolysis Revisited" [31].

\section{Application of simple and extended forms of the Grunwald-Winstein equation}

For a rigid explanation of how the substitution reactions of sulfonyl chlorides proceed during solvolysis, a detailed picture of the influence of the solvent as one proceeds from reactants to products, such as one developed based on the procedures outlined above [31] would be required. However, if one is willing to settle for a classification of the mechanism as unimolecular or bimolecular accompanied by an approximate measure of the extents of bond-making and bond-breaking at the sulfur 
atom involved at the transition state, one can use a linear free energy relationship (LFER) approach [32].

Probably the best known LFER is the Hammett equation which presents a way of correlating the behavior of reactants with a substituent present in an aromatic ring with the effect of that substituent on the acidity of benzoic acids in water at $25^{\circ} \mathrm{C}$. As one would expect as once moves away from the standard reaction, the goodness of fit of the data using the Hammett substituent constants will be decreased. For example, for phenols which have a direct conjugation of a developing anion with an appropriate substituent, adjusted $\sigma$ values are available for these substituents.

The above is presented to give some background to the approach that can be used to give one type of information that can be useful in studies of solvolysis reactions in which the solvent for the substrate is also the reactant. The substrates that are being correlated are those which can give substitution products, in many (but not all) cases accompanied by elimination products. The original equation was developed by Grunwald and Winstein in 1948 [33] and, on the occasion of its sixtieth birthday, the authors of the present review published a brief account of the development and uses to commemorate the occasion [34].

Accordingly, we will be somewhat brief in the introduction to this treatment before discussing its application to a study of solvolyses taking place at the sulfur atom of sulfonyl chlorides. The original scale of solvent ionizing power $(Y)$ values was based on a study of the solvolyses of tert-butyl chloride in a variety of aqueous/organic solvents at $25.0{ }^{\circ} \mathrm{C}$ and the LFER was expressed as in Equation 1, where $k_{\mathrm{O}}$ is the specific rate (first-order rate coefficient) for solvolyses in the arbitrarily chosen standard solvent of $80 \%$ ethanol and $20 \%$ water (by volume) and $k$ is the corresponding specific rate in some other pure or mixed solvent. The sensitivity value $m$ is set at unity for the standard solvolysis and then for some other solvent the solvent ionizing power $(Y)$ will be given by $\log \left(k / k_{\mathrm{o}}\right)$. Subsequently, with the ready availability of cage compounds (1-adamantyl and 2-adamantyl with a leaving group X), the moderate to weak nucleophilic participation with tert-butyl derivatives [35] can be avoided. The more reactive $3^{\circ}$ compound is used to set up scales of $Y$ values for the relatively poor leaving groups and the less reactive $2^{\circ}$ compound is used for the relatively good leaving groups [25].

$$
\log \left(k / k_{o}\right)=m Y
$$

In the majority of solvolysis reactions, one also needs to evaluate the nucleophilic attack by the solvent which contributes modestly to the overall scheme for tert-butyl chloride solvolyses but appreciably for the solvolyses of methyl and primary alkyl halides. The original Grunwald-Winstein equation can be expanded to give a two-term Equation 2 [34,36,37], where $l$ is the sensitivity to changes in $N$, which is a measure of solvent nucleophilicity. The original $N$ scale was based on the specific rates of solvolysis of methyl tosylate [38] but, with this as the standard, there is a significant problem in assigning the required $m$ value for use in the two-term equation. This problem was minimized by use of the $S$-methyldibenzothiophenium ion $\mathrm{MeDBTh}^{+}$(as the trifluoromethanesulfonate) as the standard substrate $[39,40]$ (Scheme 2). This solvolysis has as the leaving group a neutral molecule, dibenzothiophene, and it was shown from studies of 1-adamantyl derivatives [36] that ionic substrates of this type solvolyze in $S_{N} 1$ reactions with very little variation in specific rate with changes in solvent. The solvent nucleophilicity scale developed is termed $N_{\mathrm{T}}$ scale $[36,37]$ and $N_{\mathrm{T}}=\log \left(k / k_{\mathrm{o}}\right)_{\mathrm{MeDBTh}}{ }^{+}$; where $k_{\mathrm{o}}$ is the value in $80 \%$ ethanol ( $20 \%$ water) and $k$ is the value of the specific rate of solvolysis in another solvent of interest.

$$
\log \left(k / k_{o}\right)=l N+m Y
$$
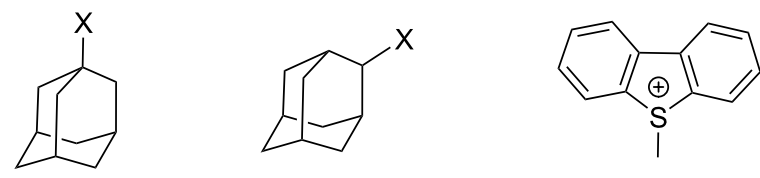

Scheme 2: The chemical structures for the 1-adamantyl substrate, 2-adamantyl substrate, and the S-methyldibenzothiophenium ion $\left(\mathrm{MeDBTh}^{+}\right)$. In the 1- and 2-substituted adamantyl substrates, $X$ represents the anionic leaving group.

If a given solvolysis, such as of an alkyl chloride, is studied over a wide range of solvent types such as from ethanol $\left(N_{\mathrm{T}}=\right.$ 0.37; $Y_{\mathrm{Cl}}=-2.52$ to $97 \%$ HFIP $(1,1,1,3,3$,3-hexafluoro-2propanol $/ 3 \% \mathrm{H}_{2} \mathrm{O}$, by weight) with values of -5.26 for $N_{\mathrm{T}}$ and 5.17 for $Y_{\mathrm{Cl}}$, a discontinuity is sometimes observed in the plot. This discontinuity can usually be taken as evidence for a change in mechanism from bimolecular to unimolecular as is found, for example, in a study of the solvolyses of ethyl chloroformate or ethyl chlorothioformate, where there is a change in mechanism from bimolecular to unimolecular as one goes to more ionizing and less nucleophilic solvents [41]. In other instances, a good linear plot is obtained over a wide range of solvents, showing a strong tendency for either the unimolecular (low $l$ value and high $m$ value), as in the solvolyses of tert-butyl chloride [25,35], or a tendency to bimolecular solvolyses (high $l$ value and intermediate $m$ value, as is very well illustrated in a correlation of the rates of solvolyses of phenyl chloroformate [42]. 
When applying to the solvolyses of sulfonyl chlorides, with substitution resulting from attack at sulfur and not at carbon, there is another consideration involving the assumption that $N_{\mathrm{T}}$ and $Y_{\mathrm{Cl}}$ scales set up using substitution at carbon will also be applicable to substitution at sulfur. Those studies discussed in this review which involve the application of the extended Grunwald-Winstein equation should, through a consideration of goodness-of-fit parameters, such as correlation coefficient and $F$-test value, allow this question to be answered.

\section{Studies by Bentley and co-workers}

Koo, Bentley, Kang, and Lee [43] studied the solvolysis of 2,4,6-trimethylbenzenesulfonyl chloride in a mixture of water with acetone, acetonitrile, dioxane, ethanol or methanol in terms of rates of reaction and also product selectivities for the binary hydroxylic solvents, where both of the components (usually water plus an alcohol), can lead to products. Plots against $Y_{\mathrm{Cl}}$ values [35] were considered to give evidence for two reaction channels. Similar behavior was observed for the solvolysis of other electron-rich benzenesulfonyl chlorides [44] and for 2,4,6triisopropylbenzenesulfonyl chloride [45], except that in the latter case the plot was against $Y$ values [25,33]. Such an assignment needs to be treated with caution because the large contributions from solvent nucleophilicity effects to these solvolyses $[16,17,26,27,30]$, even with electron-rich substrates, would be expected to lead to perturbations of plots against only solventionizing power.

Shallow maxima observed when selectivity values $(S$, indicating the extent of product formation involving replacement of the chloride by the alkoxy group from an alcohol molecule reactive to replacement by the hydroxy group of a water molecule) could be due to two reaction channels varying in importance as the solvent composition is varied [43-45] but, as was shortly thereafter pointed out by Bentley and co-workers [46-48], the ratio will be influenced by a general base catalysis by a second alcohol or water molecule to the nucleophilic attack by the first alcohol or water molecule, leading to four possible reaction pathways, with two leading to replacement of the chloride by an alkoxy group and two to replacement by a hydroxy group.

In a 2007 article [49] with "Dual Reaction Channels" in both the title and the "Key Words," there is extensive dispersal between the plots against $Y_{\mathrm{Cl}}$ for different aqueous organic solvents, with the $97 \%$ TFE point lying considerably below the other points, Arrhenius plots (3 temperatures) showed modest activation energies and very negative entropies of activation, consistent with an $S_{N} 2$ process. The $S_{N} 2$ process was given considerable support by the observation that an extended Grunwald-Winstein plot gave a very good correlation with all data points close to the linear plot. A maximum in selectivity values, consistent with a duality of mechanism was observed for aqueous ethanol but not for aqueous methanol. We will return to this system when, under a later subheading, we discuss applications of the extended Grunwald-Winstein equation [36-39].

Sulfonyl chlorides have relatively high heterolytic bond-dissociation energies [50] indicating that under the usual solvolytic conditions the formation of sulfonyl cations will be unfavorable. The mechanism is best considered as dominantly $\mathrm{S}_{\mathrm{N}} 2$, but possibly with some $S_{N} 1$ character, even in water or $97 \%$ TFE [51].

It has been proposed that, in addition to having an alcohol or water as the attacking nucleophile with a second alcohol of water as a general base, one can proceed in an alcoholysis reaction through a cyclic structure involving three molecules of the alcohol and the sulfur of the sulfonyl chloride present in the ring [52]. One would predict that such an extremely ordered pathway would have a very negative entropy of activation, but the required studies with temperature variation to investigate this aspect were not reported.

In reading the section "Substitutions at Sulphur" in the second edition of Ingold's classical "Structure and Mechanism in Organic Chemistry" text [53], it is surprising to see that the section starts with the statement "No kinetic studies defining mechanisms of nucleophilic substitution at sulphur are known to the writer...". Examination of this section of the text shows, however, that it is limited to a consideration of substitution at the sulfur of sulfinates and reactions of the general type illustrated in Equation 3 and reactions involving sulfonates are not considered.

\section{$\mathrm{ArSOOR}+\mathrm{R}^{\prime} \mathrm{OH} \longrightarrow \mathrm{ArSOOR}+\mathrm{ROH}$}

The hydrolyses in 1\% dioxane/99\% water have been studied at several temperatures by Houghton, Laird, and Spence for 27 variously substituted benzenesulfonyl chlorides [54]. They proposed that, consistent with previous reports, all reacted by a bimolecular nucleophilic substitution taking place at the sulfur.

\section{Consideration of evidence from applications of the extended Grunwald-Winstein equation}

Consistent with the bimolecular nature of the solvolyses of alkanesulfonyl chlorides and arenesulfonyl chlorides [49,5567], poor correlations are obtained when the logarithmic rate data are correlated against only $Y_{\mathrm{Cl}}$ values, using Equation 1. When the $m Y_{\mathrm{Cl}}$ term is joined by the $l N_{T}$ term (Equation 2), the application to sulfonyl chlorides varying from relatively simple to fairly complex structures (Table 1), and with use of solvents 
Table 1: Molecular structures of sulfonyl chlorides $\left(\mathrm{ZSO}_{2} \mathrm{Cl}\right)$ which have been studied kinetically in terms of the extended Grunwald-Winstein equation and/or in terms of kinetic solvent isotope effects ( $k_{\text {sie }}$ values) with relevant references.

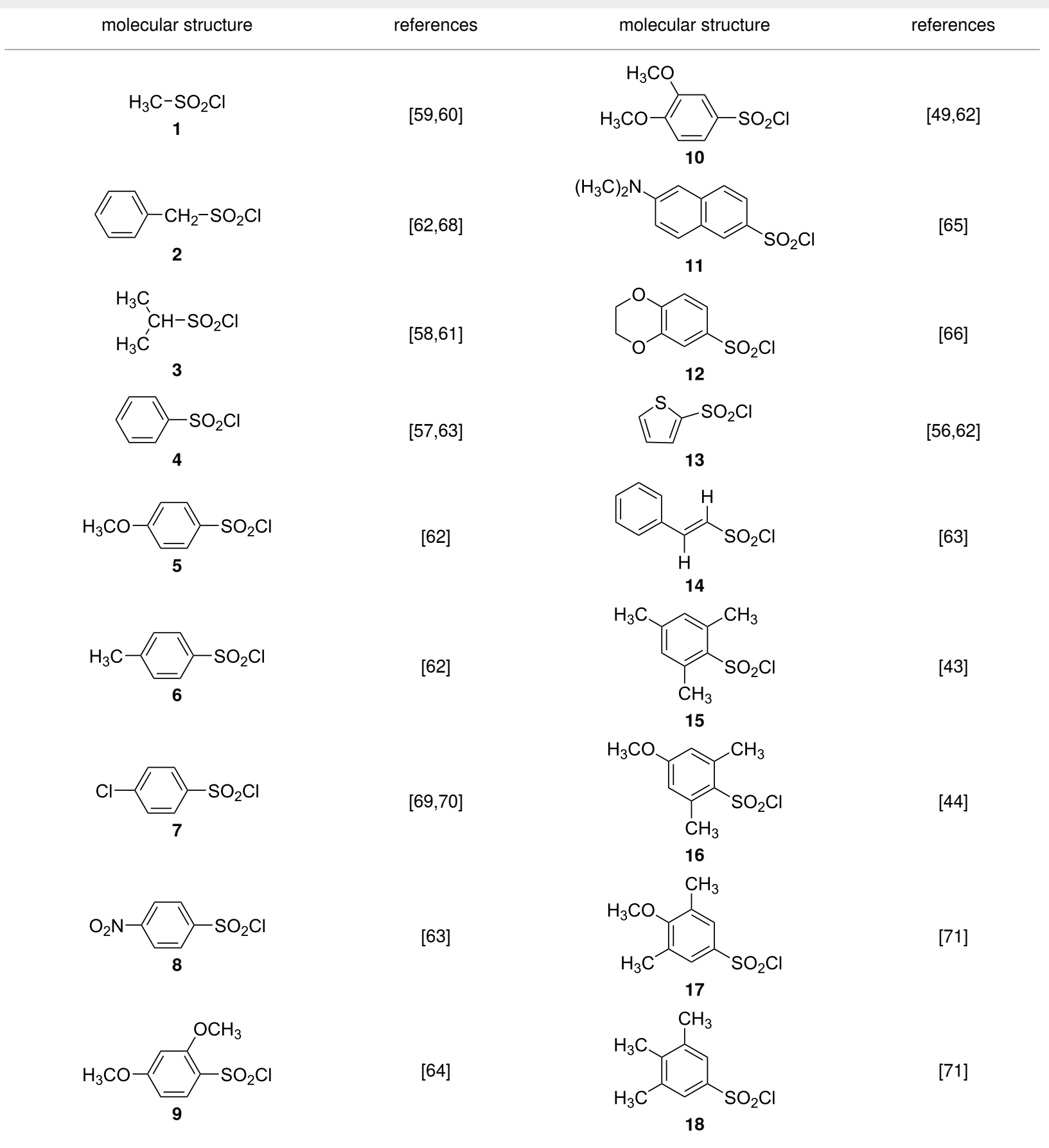

varying from aqueous acetone to aqueous fluoroalcohols, leads to acceptable to very good correlations, as assessed in terms of the accompanying correlation coefficients $(R)$ and F-test values $(F)$.

In Table 2 are assembled the calculated $l, m$, and $c$ values (Equation 2), obtained from correlations in 19-43 solvents for thirteen sulfonyl chlorides (structures presented in Table 1), containing very simple to fairly complex substrates, which can be considered as aryl, arylalkyl, arylalkenyl, or heteroaryl sulfonyl chlorides. (1 through 6 and 8 through 14 in Table 1 and these identifiers are used, and references $[49,56-66,68])$.

It is found that, for the thirteen substrates, the $l / m$ ratios vary only over a rather narrow range of 1.43 to 2.39 . These values result from $l$ and $m$ values which are typical for $\mathrm{S}_{\mathrm{N}} 2$ substitu- 
Table 2: Correlation of the specific rates of solvolytic displacement of chloride ions by nucleophilic interaction at the sulfur of sulfonyl chlorides $\left(\mathrm{RSO}_{2} \mathrm{Cl}\right)$ whose structures are tabulated and related to compound numbers in Table 1.

\begin{tabular}{|c|c|c|c|c|c|c|c|c|c|}
\hline Compound $^{\mathrm{a}}$ & $T,{ }^{\circ} \mathrm{C}^{\mathrm{b}}$ & $n^{c}$ & $l^{\mathrm{d}}$ & $m^{\mathrm{d}}$ & $c^{\mathrm{e}}$ & $R^{f}$ & $F^{g}$ & $\mathrm{I} / \mathrm{m}$ & Lit. $^{h}$ \\
\hline 1 & 45.0 & 39 & $1.17 \pm 0.04$ & $0.49 \pm 0.02$ & 0.23 & 0.981 & 454 & 2.39 & {$[59,60]$} \\
\hline \multirow[t]{2}{*}{2} & 45.0 & 29 & $0.87 \pm 0.10$ & $0.46 \pm 0.06$ & 0.09 & 0.874 & 42 & 1.89 & {$[62,68]$} \\
\hline & 45.0 & $23^{\mathrm{i}}$ & $0.80 \pm 0.06$ & $0.39 \pm 0.04$ & 0.21 & 0.947 & 95 & 2.05 & [62] \\
\hline 3 & 45.0 & 19 & $1.28 \pm 0.05$ & $0.64 \pm 0.03$ & 0.18 & 0.988 & 333 & 2.00 & {$[58,61]$} \\
\hline 4 & 35.0 & 29 & $1.26 \pm 0.05$ & $0.65 \pm 0.03$ & 0.13 & 0.979 & 304 & 1.94 & {$[57,63]$} \\
\hline 5 & 25.0 & 38 & $1.07 \pm 0.08$ & $0.60 \pm 0.03$ & 0.22 & 0.967 & 254 & 1.78 & [62] \\
\hline 6 & 25.0 & 34 & $1.19 \pm 0.07$ & $0.61 \pm 0.02$ & 0.20 & 0.975 & 305 & 1.95 & {$[62]$} \\
\hline 8 & 35.0 & 21 & $1.52 \pm 0.09$ & $0.66 \pm 0.05$ & 0.10 & 0.968 & 134 & 2.30 & [63] \\
\hline 9 & 25.0 & 30 & $0.93 \pm 0.14$ & $0.65 \pm 0.06$ & & 0.918 & & 1.43 & [64] \\
\hline 10 & 25.0 & 40 & $1.24 \pm 0.07$ & $0.64 \pm 0.03$ & 0.14 & 0.967 & 264 & 1.94 & {$[49,62]$} \\
\hline 11 & 35.0 & 31 & $0.96 \pm 0.09$ & $0.53 \pm 0.03$ & 0.10 & 0.955 & & 1.81 & [65] \\
\hline 12 & 25.0 & 28 & $1.00 \pm 0.07$ & $0.59 \pm 0.03$ & & 0.948 & & 1.69 & [66] \\
\hline 13 & 25.0 & 34 & $1.35 \pm 0.05$ & $0.70 \pm 0.02$ & 0.28 & 0.983 & 455 & 1.93 & {$[56,62]$} \\
\hline 14 & 45.0 & 43 & $1.24 \pm 0.04$ & $0.58 \pm 0.02$ & 0.07 & 0.982 & 542 & 2.14 & [63] \\
\hline
\end{tabular}

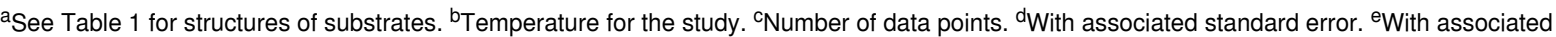
standard error of 0.04 to 0.06 , except 0.09 for $\mathbf{8}$. ${ }^{\mathrm{f} C o r r e l a t i o n}$ coefficient. $\mathrm{g} F$-test value. ${ }^{\mathrm{h} P u b l i c a t i o n s}$ from which the data points were assembled. 'Values for 2,2,2-trifluoroethanol/ethanol mixtures omitted.

tions The $l$ values, sensitivities to changes in solvent nucleophilicity, are all close to unity (range of 0.80 to 1.52 ). This is to be expected because the prototype for $\mathrm{S}_{\mathrm{N}} 2$ solvolyses, which involves solvolyses at the methyl carbon of a methyl derivative is set at unity, for either the solvolyses of methyl $p$-toluenesulfonate [38] or of the $S$-methyldibenzothiophenium ion [39] when used as the standard $\mathrm{S}_{\mathrm{N}} 2$ substrate for solvolyses over a wide range of solvents and the range of $l$ values suggests that the addition-elimination pathway appears to be disfavored for sulfonyl chlorides. The $m$ values (Table 2) are consistent with the solvation electronics observed with the chloride leaving group in bimolecular processes [34].

For two of the systems studied, involving the substrates $\mathbf{4}$, and 13 of Table 1, the application of Equation 2 is illustrated in Figure 1 and Figure 2. In both instances good linear plots are obtained. Substrate $\mathbf{2}$ is of considerable interest because, if the solvolysis is carried out in a deuterated solvent of type ROD in the presence of the conjugate base $\left(\mathrm{OR}^{-}\right)$, it is found that there is deuterium uptake into the product. This is believed to be excellent evidence for the intermediacy of a sulfene formed by an elimination reaction promoted by the $\mathrm{OR}^{-}$species, with the sulfene then rapidly adding a solvent molecule to give a final product which is identical to the direct substitution product, except that, with the deuterated solvent, deuterium uptake can easily be detected [72-74] (Equation 4). This reaction was found to occur only in the presence of reasonably high concentrations of the conjugate base of the alcohol solvent and it would not normally be observed under neutral solvolysis conditions.

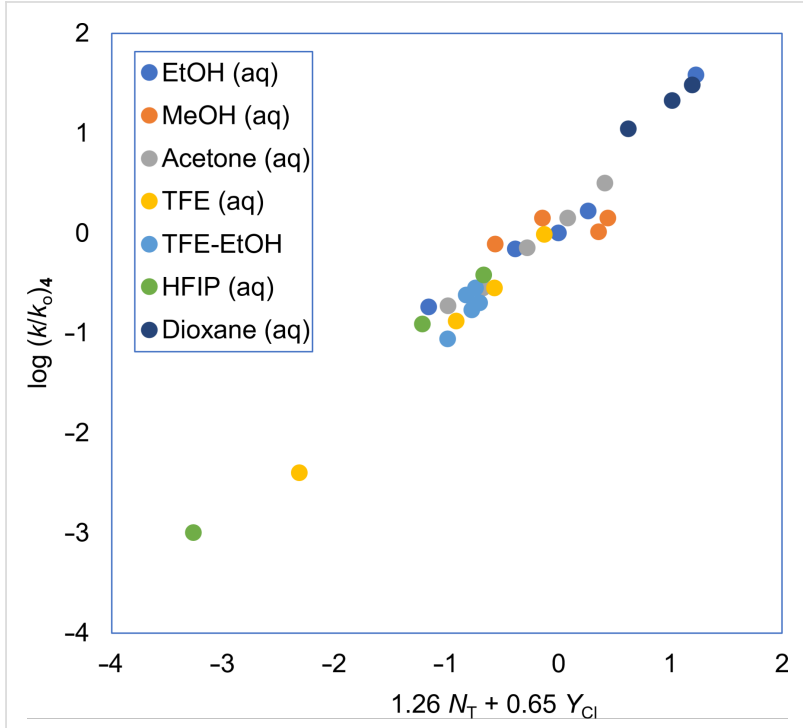

Figure 1: The $S_{\mathrm{N}} 2$ reaction plot of $\log \left(k / k_{0}\right)$ vs $\left(1.26 N_{\mathrm{T}}+0.65 \mathrm{Y}_{\mathrm{Cl}}\right)$ for the solvolyses of benzesulfonyl chloride (4) in pure and binary solvents at $35.0^{\circ} \mathrm{C}$. Figure 1 was redrawn using the data points from [63] ("Correlation of the Rates of Solvolysis of Two Arenesulfonyl Chlorides and of trans- $\beta$-Styrenesulfonyl Chloride - Precursors in the Development of New Pharmaceuticals“, (c) 2008 Z. H. Ryu et al., distributed under the terms of the Creative Commons Attribution 3.0 International License, https://creativecommons.org/licenses/by/3.0).

$\mathrm{C}_{6} \mathrm{H}_{5} \mathrm{CH}_{2} \mathrm{SO}_{2} \mathrm{Cl} \underset{\mathrm{ROD}}{\stackrel{\mathrm{OR}^{-}}{\longrightarrow}} \mathrm{C}_{6} \mathrm{H}_{5} \mathrm{CH}=\mathrm{SO}_{2} \stackrel{\mathrm{ROD}}{\longrightarrow} \mathrm{C}_{6} \mathrm{H}_{5} \mathrm{CHDSO}_{2} \mathrm{OR}$

King has also studied the hydrolysis when the simplest structure for a tertiary alkyl group, the tert-butyl group, is attached to 


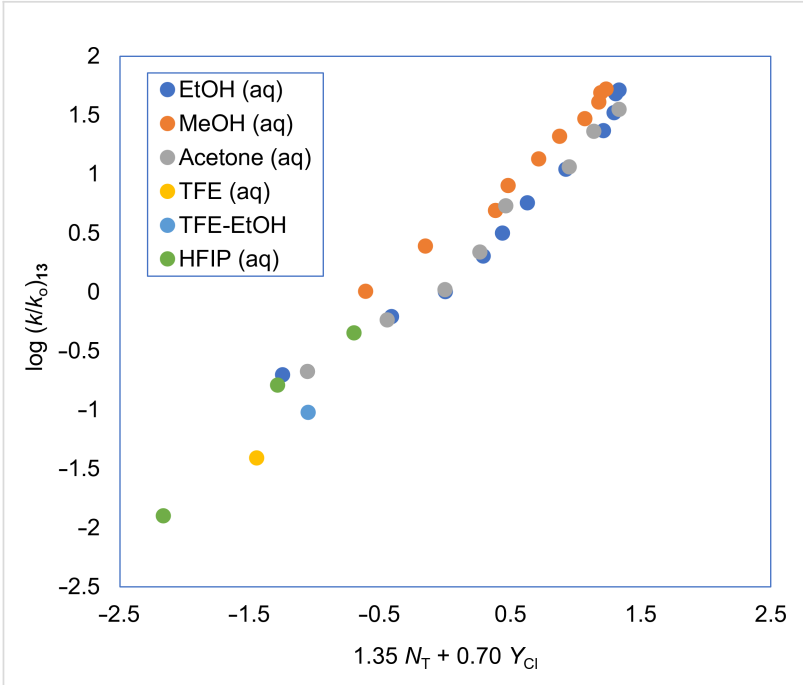

Figure 2: The $S_{N} 2$ reaction plot of $\log \left(k / k_{0}\right)$ vs $\left(1.35 N_{T}+0.70 Y_{C l}\right)$ for the solvolyses of 2-thiophenesulfonyl chloride (13) in pure and binary solvents at $25.0^{\circ} \mathrm{C}$. The specific rate values are from [56] and [62].

the sulfur of the sulfonyl group. Solvolysis of 2-methyl-2propanesulfonyl chloride was found [75] to give evidence for the tert-butyl cation formation. It was proposed that the chlorosulfonyl group is about half as nucleofugic as a chloride ion (irrespective of whether it leaves intact on the $\mathrm{SO}_{2} \mathrm{Cl}^{-}$ion or as $\mathrm{SO}_{2}+\mathrm{Cl}^{-}$) (Equation 5)

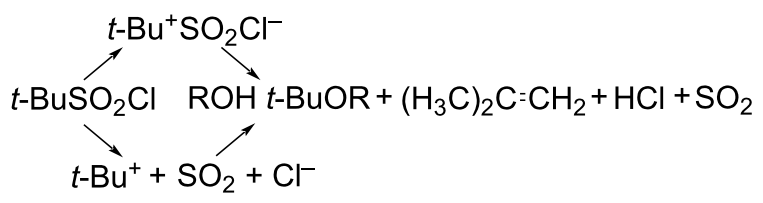

It would be of interest to extend this study to other $\mathrm{RSO}_{2} \mathrm{Cl}$ substrates, where the $\mathrm{R}$ forms a relatively stable carbocation, such as the 1-adamantanesulfonyl chloride and/or the diphenylmethanesulfonyl chloride $\left[\left(\mathrm{C}_{6} \mathrm{H}_{5}\right)_{2} \mathrm{CHSO}_{2} \mathrm{Cl}\right]$, examples with intermediate cations which one would predict to be less stable and more stable, respectively, than the tert-butyl cation. These additional studies would be somewhat simplified in that an alkene, observed as a product from 2-methyl-2-propanesulfonyl chloride, would not be formed from the 1-adamantanesulfonyl or diphenylmethanesulfonyl chlorides.

While it is desirable to obtain information as regards the importance of solvent nucleophilicity as a rate-determining factor as above, from consideration in a sufficient number (twenty is a reasonable lower limit) of well-chosen (good variety as regards the combinations of $N$ and $Y$ values) solvents, this is a timeconsuming process. If only an approximate value is required one can use the $k_{4 \mathrm{OE}} / k_{97 \mathrm{TFE}}$ ratio from measurements of the rates of solvolysis in only $40 \% \mathrm{EtOH}(\mathrm{v} / \mathrm{v})$ and $97 \% \mathrm{TFE}(\mathrm{w} / \mathrm{w})$ [25]. These solvents have virtually identical $Y_{\mathrm{Cl}}$ values of 2.75 and 2.83 , respectively, but very different $N_{\mathrm{T}}$ values of -0.74 and -3.30 , respectively [37], accordingly for these two mixed solvents, the logarithm of the ratio of the solvolysis rate for a given substrate in these two solvents $\left(k_{4 \mathrm{OE}} / k_{97 \mathrm{TFE}}\right)$ will be governed almost entirely by $2.56 l$ (Equation 6).

$$
\log \left(k_{40 \mathrm{E}} / k_{97 \mathrm{TFE}}\right)=2.56 l
$$

To take an example, for compound $\mathbf{1 4}$, a value for $l$ of 1.14 is obtained as opposed to a value of $(1.24 \pm 0.04)$ from the more rigorous extended Grunwald-Winstein equation treatment [63] (Table 2). Truncated comparisons of this general type had been earlier proposed by Cafferata and co-workers in a study of the solvolyses of alkyl fluorosulfates [76].

In discussing the $k_{4 \mathrm{OE}} / k_{97 \mathrm{TFE}}$ ratios, a good starting point is with the bridgehead-substituted 1-adamantyl chlorides, where a rear side $S_{N} 2$ process is impossible, with a value for the ratio of 0.83 . The ratio raises to 1.38 for the tosylate but such variations are to be expected because different anionic nucleofuges do respond slight differently to solvent variation [25]. Inspection of Table 2 shows that the actual value for the ratio is sufficiently raised from unity for all the required substrates for which the required value in $97 \%$ TFE is available for them to be classified as bimolecular solvolyses. However, the values for the ratio do show a large variation, with a range from 74 for the 2,4dimethylbenzenesulfonyl chloride (8) to 15000 for the $p$-nitrobenzenesulfonyl chloride (7). It is noteworthy that the ratio for the unsubstituted compound $\mathbf{4}$ of 2900 is reduced to 450 with a $p$-Me substituent (5) and further reduced to 300 with a $p$-MeO substituent (6), both electron-supplying substituents. It was reduced only slightly to 2430 in the presence of a $p-\mathrm{Cl}$ substituent and, as mentioned above, raised appreciably to 15000 in the presence of a powerfully electron-withdrawing $p-\mathrm{NO}_{2}$ group.

\section{Evidence as regards the reaction mechanism from kinetic solvent isotope effect $\left(k_{\text {sie }}\right)$ measurements}

Initial studies of solvent isotope effects in solvolysis reactions were largely carried out by comparing rates in $\mathrm{H}_{2} \mathrm{O}$ with those in $\mathrm{D}_{2} \mathrm{O}$ [75]. Low solubilities for many of the organic substrates studied [28] led to the adoption of studies in methanol and methanol- $d$ as a favored alternative. It has been found, however, that for solvolysis of sulfonyl chlorides this factor is not as important as initially thought and solubilities in water are, for most (but not all) sulfonyl chlorides, usually sufficient for both $k_{\mathrm{H} 2 \mathrm{O}} / k_{\mathrm{D} 2 \mathrm{O}}$ and $k_{\mathrm{MeOH}} / k_{\mathrm{MeOD}}$ ratios to be attainable in the temperature range of $15-45^{\circ} \mathrm{C}$ (Table 3 ). 
Table 3: The specific rate ratios for solvolyses in $40 \%$ ethanol/ $60 \% \mathrm{H}_{2} \mathrm{O}(\mathrm{v} / \mathrm{v})$ relative to those in $97 \%$ TFE/3\% $\mathrm{H}_{2} \mathrm{O}\left(\mathrm{w} / \mathrm{w}\right.$ ), $k_{40 \mathrm{E}} / \mathrm{k}_{97 \mathrm{TFE}}$, and the kinetic solvent isotope effect $\left(k_{\text {sie }}\right)$ for solvolyses in methanol relative to solvolyses in methanol- $d\left(k_{\mathrm{MeOH}} / k_{\mathrm{MeOD}}\right)$ and for solvolyses in $\mathrm{H}_{2} \mathrm{O}$ relative to solvolyses in $\mathrm{D}_{2} \mathrm{O}\left(k_{\mathrm{H} 2 \mathrm{O}} / k_{\mathrm{D} 2 \mathrm{O}}\right)$. The values for the ratios are at $25.0^{\circ} \mathrm{C}$ unless otherwise stated.

\begin{tabular}{|c|c|c|c|c|c|c|}
\hline Substrate & $k_{40 \mathrm{E}} / k_{97 \mathrm{TFE}}$ & Lit. & $k_{\mathrm{MeOH}} / k_{\mathrm{MeOD}}$ & Lit. & $k_{\mathrm{H} 2 \mathrm{O}} / k_{\mathrm{D} 2 \mathrm{O}}$ & Lit. \\
\hline 1 & $2010\left(45^{\circ} \mathrm{C}\right)$ & {$[59,60]$} & $1.62 ; 1.51\left(35^{\circ} \mathrm{C}\right)$ & {$[63]$} & $1.64\left(18^{\circ} \mathrm{C}\right) ; 1.57\left(20^{\circ} \mathrm{C}\right)$ & [28] \\
\hline 2 & no value for $97 \%$ TFE & & $2.34\left(35^{\circ} \mathrm{C}\right)$ & [68] & very low solubility & \\
\hline 3 & $2790\left(45^{\circ} \mathrm{C}\right)$ & {$[63]$} & $2.54 ; 2.41\left(35^{\circ} \mathrm{C}\right)$ & {$[61]$} & $1.66 ; 1.45\left(35^{\circ} \mathrm{C}\right)$ & {$[61]$} \\
\hline 4 & 2900 & {$[63]$} & 1.79 & {$[71]$} & $\begin{array}{c}1.56\left(20^{\circ} \mathrm{C}\right) \\
1.59 \\
1.58\left(15^{\circ} \mathrm{C}\right)\end{array}$ & $\begin{array}{l}{[28]} \\
{[71]} \\
{[30]}\end{array}$ \\
\hline 5 & 300 & {$[63]$} & 1.58 & {$[71]$} & $\begin{array}{c}1.37 \\
1.41\left(15^{\circ} \mathrm{C}\right)\end{array}$ & $\begin{array}{l}{[71]} \\
{[30]}\end{array}$ \\
\hline 6 & 450 & {$[63]$} & 1.72 & {$[71]$} & $\begin{array}{c}1.49 \\
1.50\left(15^{\circ} \mathrm{C}\right)\end{array}$ & $\begin{array}{l}{[71]} \\
{[30]}\end{array}$ \\
\hline 7 & 2430 & {$[69,70]$} & 1.89 & {$[71]$} & 1.65 & {$[71]$} \\
\hline 8 & 15000 & [63] & 2.31 & {$[71]$} & $\begin{array}{c}1.76 \\
1.82\left(15^{\circ} \mathrm{C}\right)\end{array}$ & $\begin{array}{l}{[71]} \\
{[30]}\end{array}$ \\
\hline 9 & 74 & {$[64]$} & 1.74 & {$[64]$} & 1.86 & {$[64]$} \\
\hline 10 & 386 & {$[49]$} & 1.45 & [49] & 1.35 & [49] \\
\hline 11 & no value for $97 \%$ TFE & & 1.88 & [65] & & \\
\hline 12 & & & 1.62 & {$[66]$} & & \\
\hline 13 & no value for $97 \%$ TFE & & 2.34 & {$[56]$} & 1.47 & [56] \\
\hline 14 & $85\left(45^{\circ} \mathrm{C}\right)$ & {$[63]$} & $1.76\left(45^{\circ} \mathrm{C}\right)$ & {$[63]$} & $1.46\left(45^{\circ} \mathrm{C}\right)$ & [63] \\
\hline 15 & 202 & {$[43]$} & & & & \\
\hline 16 & 89 & {$[44]$} & & & & \\
\hline $\mathrm{CF}_{3} \mathrm{SO}_{2} \mathrm{Cl}$ & no value for $97 \%$ TFE & & $3.08\left(45^{\circ} \mathrm{C}\right)$ & {$[67]$} & $2.24\left(45^{\circ} \mathrm{C}\right)$ & [67] \\
\hline 17 & & & 1.58 & {$[71]$} & 1.41 & {$[71]$} \\
\hline 18 & & & 1.68 & {$[71]$} & 1.34 & {$[71]$} \\
\hline
\end{tabular}

aThe substrates corresponding to the substrate numbers are listed in Table 1.

Since the solvent isotope effects are quite small, ratios not far removed from unity in almost all cases, precise temperature control has to be coupled with a similarly precise method for obtaining the specific rates of solvolysis. When a strong acid is produced, as in Equation 7, conductivity measurements are usually the method of choice $[31,77,78]$.

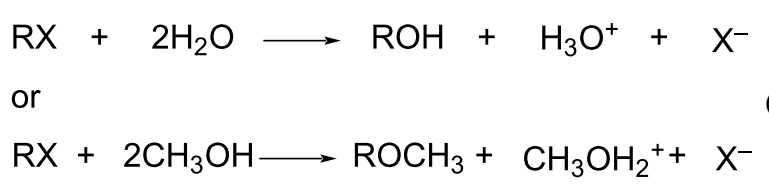

While very accurate measurements have been made, the ratios $k_{\mathrm{H} 2 \mathrm{O}} / k_{\mathrm{D} 2 \mathrm{O}}$ and $k_{\mathrm{MeOH}} / k_{\mathrm{MeOD}}$ have not proved to be very useful in assigning a structure to the transition state. One can in this regard quote Hammett from the second edition of his classical "Physical Organic Chemistry" text [79] "The hope, which at one time seemed bright, for a simple correlation of the solvent isotope effect with the mechanism of a reaction involving proton transfer or with the stoichiometric involvement of the solvent at the transition state has proved vain."

Rossall and Robertson [30] found that, in the hydrolyses of para-substituted benzenesulfonyl chloride, the $k_{\mathrm{sie}}\left(k_{\mathrm{H} 2 \mathrm{O}} / k_{\mathrm{D} 2 \mathrm{O}}\right)$ increased in value as one goes from substrates with a $p-\mathrm{MeO}$ to the parent and on to the $p-\mathrm{NO}_{2}$-substituted substrate. Within Table 3, this corresponds to going from solvolyses of $\mathbf{5}$ to $\mathbf{6}$ to $\mathbf{4}$ to 7 and on to 8 (values of $1.37,1.49,1.59,1.65$, and 1.76 at $25.0{ }^{\circ} \mathrm{C}$ ) and, for changes in $k_{\mathrm{MeOH}} / k_{\mathrm{MeOD}}$, values also increase steadily in the same sequence (values of 1.58, 1.72, 1.79, 1.89, and 2.31 at $25.0^{\circ} \mathrm{C}$ ) [71]. It was believed that these results, which differ dramatically from the very low sensitivity to structural change at a saturated carbon atom, reflect a more pronounced bondmaking by the solvents at the transition state for solvolyses of sulfonyl chlorides, involving attack at sulfur, than for attack at a saturated carbon atom. There is in Table 3 quite a number of values which have been reported on the basis of different investigations. It is noteworthy that there is uniformly a good agreement between these values and a firm 
foundation for attempts at an explanation. However, what Hammett pointed out [79] several years ago is still relevant today.

The section of the "Solvolysis Revisited" review [31] dealing with kinetic solvent isotope effects (pages 168-169) illustrates the extreme complexity of this topic and the uncertainty as to the extents to which the $k_{\text {sie }}$ values are due to differences in initial states, due to differences in the chemical potentials of the transition state [80], or due to some other, as yet unidentified, source.

As a final topic, it is possible, indeed probable, that the complex associative structures in water and to a lesser extent in methanol lead to the simple two molecule formulation of the $\mathrm{S}_{\mathrm{N}} 2$ process for the hydrolysis being an oversimplification. The observation that the small molecule $\mathrm{H}_{2} \mathrm{O}$ is in bulk a liquid at room temperature requires a dynamic situation where water molecules are to a large extent associated by hydrogen-bonding to give dimers and larger aggregates. The $\mathrm{S}_{\mathrm{N}} 2$ process could therefore involve monomers, dimers and even larger aggregates as regards the attacking species. The dimers and larger aggregates can be considered as leading to general-base catalysis to an $\mathrm{S}_{\mathrm{N}} 2$ process. Alternatively, the process with attack by a dimer can be described as an $\mathrm{S}_{\mathrm{N}} 3$ process and, presumably, attack by a trimer would be $\mathrm{S}_{\mathrm{N}} 4$ and so forth. There is nothing wrong with either of these formulations provided the processes are suitably defined. Such a definition and explanation are given in Scheme 1 of the 2009 paper [69] by Bentley, Jones, Kang and Koo.

The present authors take into account the original Hughes and Ingold "Designation of Mechanism" [81]. "The molecularity of a reaction stage is defined as the number of molecules necessarily undergoing covalency changes," (emphasis added), and for a composite reaction it is conveniently designated as "the molecularity of the rate-determining stage." We personally favor the designation as bimolecular with or without general-base assistance from a second nucleophilic (basic) molecule.

\section{Acknowledgements}

This article's opinions and views are those of the authors and do not necessarily reflect any federal and state funding agencies' opinions and beliefs.

\section{Funding}

MJD acknowledges support from a NSF-EPSCoR award (OIA1757353, WiCCED program), an IDeA award from NIHNIGMS (P20GM103446, DE-INBRE program), and the State of Delaware.

\section{ORCID ${ }^{\circledR}$ iDs}

Malcolm J. D'Souza - https://orcid.org/0000-0002-9368-790X

\section{References}

1. Gordon, I. M.; Maskill, H.; Ruasse, M.-F. Chem. Soc. Rev. 1989, 18, 123-151. doi:10.1039/cs9891800123

2. Rogne, O. J. Chem. Soc. B 1970, 727-730. doi:10.1039/j29700000727

3. Rogne, O. J. Chem. Soc., Perkin Trans. 2 1972, 489-492. doi:10.1039/p29720000489

4. Berger, G.; Olvier, S. C. J. Recl. Trav. Chim. Pays-Bas 1927, 48, 516-527.

5. Hammett, L. P. J. Am. Chem. Soc. 1937, 59, 96-103. doi:10.1021/ja01280a022

6. Hammett, L. P. Physical Organic Chemistry, 2nd ed.; McGraw Hill: New York, NY, USA, 1970.

7. Hedlund, I. Ark. Kemi, Mineral. Geol. 1940, 14A, 1-17.

8. Böhme, H.; Schürhoff, W. Chem. Ber. 1951, 84, 28-47. doi:10.1002/cber.19510840106

9. Swain, C. G.; Scott, C. B. J. Am. Chem. Soc. 1953, 75, 141-147. doi:10.1021/ja01097a041

10. Swain, C. G.; Scott, C. B. J. Am. Chem. Soc. 1953, 75, 246-248. doi:10.1021/ja01097a520

11. Kice, J. L.; Lunney, E. A. J. Org. Chem. 1975, 40, 2125-2127. doi:10.1021/jo00902a025

12. Hall, H. K., Jr. J. Am. Chem. Soc. 1956, 78, 1450-1454. doi:10.1021/ja01588a048

13. Tommila, E.; Hirsjärvi, P. Acta Chem. Scand. 1951, 5, 659-664. doi:10.3891/acta.chem.scand.05-0659

14. Vizgert, R. V. J. Gen. Chem. USSR 1962, 32, 619-623.

15. Vizgert, R. V.; Savchuk, E. K. J. Gen. Chem. USSR 1964, 34, 3437-3443.

16. Jenkins, F. E.; Hambly, A. N. Aust. J. Chem. 1961, 14, 190-204. doi:10.1071/ch9610190

17. Jenkins, F. E.; Hambly, A. N. Aust. J. Chem. 1961, 14, 205-210. doi:10.1071/ch9610205

18. Foon, R.; Hambly, A. N. Aust. J. Chem. 1962, 15, 668-683. doi:10.1071/ch9620668

19. Foon, R.; Hambly, A. N. Aust. J. Chem. 1962, 15, 684-698. doi:10.1071/ch9620684

20. Tonnet, M. L.; Hambly, A. N. Aust. J. Chem. 1970, 23, 2427-2434. doi:10.1071/ch9702427

21. Tonnet, M. L.; Hambly, A. N. Aust. J. Chem. 1970, 23, 2435-2441. doi:10.1071/ch9702435

22. Tonnet, M. L.; Hambly, A. N. Aust. J. Chem. 1971, 24, 703-712. doi:10.1071/ch9710703

23. Foon, R.; Hambly, A. N. Aust. J. Chem. 1971, 24, 713-721. doi:10.1071/ch9710713

24. Lowry, T. H.; Richardson, K. S. Mechanism and Theory in Organic Chemistry, 3rd ed.; Harper and Row: New York, NY, USA, 1987; pp 373-375.

25. Bentley, T. W.; Llewellyn, G. Prog. Phys. Org. Chem. 1990, 17, 121-158.

26. Forbes, R. M.; Maskill, H. J. Chem. Soc., Chem. Commun. 1991, 854-856. doi:10.1039/c39910000854

27. Bonifaci, R.; Forbes, R. M.; Henderson, R.; Maskill, H.; Palou, J.; Richardson, H. L.; Votsmeier, M. Gazz. Chim. Ital. 1995, 125, 569-575.

28. Robertson, R. E.; Rossall, B.; Sugamori, S. E.; Treindl, L. Can. J. Chem. 1969, 47, 4199-4206. doi:10.1139/v69-694 
29. Robertson, R. E.; Rossall, B. Can. J. Chem. 1971, 49, 1441-1450. doi:10.1139/v71-236

30. Rossall, B.; Robertson, R. E. Can. J. Chem. 1971, 49, 1451-1455. doi:10.1139/v71-237

31. Blandamer, M. J.; Scott, J. M. W.; Robertson, R. E. Prog. Phys. Org. Chem. 1985, 15, 149-196. doi:10.1002/9780470171943.ch3

32. Shorter, J. Correlation Analysis of Organic Reactivity with Particular Reference to Multiple Regression; Research Studies Press: Letchworth, UK, 1982.

33. Grunwald, E.; Winstein, S. J. Am. Chem. Soc. 1948, 70, 846-854. doi:10.1021/ja01182a117

34. Kevill, D. N.; D'Souza, M. J. J. Chem. Res. 2008, 61-66. doi:10.3184/030823408x293189

35. Bentley, T. W.; Carter, G. E. J. Am. Chem. Soc. 1982, 104, 5741-5747. doi:10.1021/ja00385a031

36. Kevill, D. N.; Anderson, S. W. J. Am. Chem. Soc. 1986, 108, 1579-1585. doi:10.1021/ja00267a030

37. Kevill, D. N. Development and Uses of Scales of Solvent Nucleophilicity. In Advances in Quantitative Structure-Property Relationships; Charton, M., Ed.; JAI Press: Greenwich, CT, USA, 1996; Vol. 1, pp 81-115. doi:10.1016/s1874-527x(96)80006-5

38. Schadt, F. L.; Bentley, T. W.; Schleyer, P. v. R. J. Am. Chem. Soc. 1976, 98, 7667-7675. doi:10.1021/ja00440a037

39. Kevill, D. N.; Anderson, S. W. J. Org. Chem. 1991, 56, 1845-1850. doi:10.1021/jo00005a034

40. Kevill, D. N.; Anderson, S. W. J. Chem. Res., Synop. 1991, 356-357.

41. Kevill, D. N.; D'Souza, M. J. J. Org. Chem. 1998, 63, 2120-2124. doi:10.1021/jo9714270

42. Kevill, D. N.; D’Souza, M. J. J. Chem. Soc., Perkin Trans. 2 1997, 257-264. doi:10.1039/a605340h

43. Koo, I. S.; Bentley, T. W.; Kang, D. H.; Lee, I. J. Chem. Soc., Perkin Trans. 2 1991, 175-179. doi:10.1039/p29910000175

44. Koo, I. S.; Bentley, T. W.; Llewellyn, G.; Yang, K. J. Chem. Soc., Perkin Trans. 2 1991, 1175-1179. doi:10.1039/p29910001175

45. Bentley, T. W.; Koo, I. S.; Llewellyn, G.; Norman, S. J. Croat. Chem. Acta 1992, 65, 575-583.

46. Bentley, T. W.; Jones, R. O. J. Chem. Soc., Perkin Trans. 2 1992, 743-744. doi:10.1039/p29920000743

47. Bentley, T. W.; Shim, C. S. J. Chem. Soc., Perkin Trans. 2 1993, 1659-1663. doi:10.1039/p29930001659

48. Bentley, T. W.; Jones, R. O.; Koo, I. S. J. Chem. Soc., Perkin Trans. 2 1994, 753-759. doi:10.1039/p29940000753

49. Koo, I. S.; Kivon, E.; Choi, H.; Yang, K.; Park, J. K.; Lee, J. P.; Lee, I.; Bentley, T. W. Bull. Korean Chem. Soc. 2007, 28, 2377-2381.

50. Bentley, T. W.; Jones, R. O. J. Phys. Org. Chem. 2007, 20 , 1093-1101. doi:10.1002/poc.1262

51. Bentley, T. W. Int. J. Mol. Sci. 2015, 16, 10601-10623. doi:10.3390/ijms160510601

52. lazykov, M.; Rublova, L.; Canle L., M.; Santaballa, J. A. J. Phys. Org. Chem. 2017, 30, e3588. doi:10.1002/poc.3588

53. Ingold, C. K. Structure and Mechanism in Organic Chemistry, 2nd ed.; Cornell University Press: Ithaca, New York, USA, 1969; pp 646-648.

54. Haughton, A. R.; Laird, R. M.; Spence, M. J. J. Chem. Soc., Perkin Trans. 2 1975, 637-643. doi:10.1039/p29750000637

55. Lee, I.; Kim, W. K. J. Korean Chem. Soc. 1978, 22, 111-116.
56. Choi, J.-C.; Oh, J.; Kang, D. H.; Koo, I. S.; Lee, I. J. Korean Chem. Soc. 1993, 37, 695-701.

57. Kevill, D. N.; D'Souza, M. J. Collect. Czech. Chem. Commun. 1999, 64, 1790-1796. doi:10.1135/cccc19991790

58. Kevill, D. N.; Park, B.-C.; Park, K.-H.; D'Souza, M. J.; Yaakoubd, L.; Mlynarski, S. L.; Kyong, J. B. Org. Biomol. Chem. 2006, 4, 1580-1586. doi:10.1039/b518129a

59. Kevill, D. N.; Ryu, Z. H.; Niedermeyer, M. A.; Koyoshi, F.; D'Souza, M. J. J. Phys. Org. Chem. 2007, 20, 431-438. doi:10.1002/poc.1168

60. Koo, I. S.; Yang, K.; An, S. K.; Lee, C.-K.; Lee, I. Bull. Korean Chem. Soc. 2000, 21, 1011-1014.

61. Koo, I. S.; Yang, K.; Shin, H. B.; An, S. K.; Lee, J. P.; Lee, I. Bull. Korean Chem. Soc. 2004, 25, 699-703.

62. D’Souza, M. J.; Yaakoubd, L.; Mlynarski, S. L.; Kevill, D. N. Int. J. Mol. Sci. 2008, 9, 914-925. doi:10.3390/ijms9050914

63. Ryu, Z. H.; Lee, S. W.; D'Souza, M. J.; Yaakoubd, L.; Feld, S. E.; Kevill, D. N. Int. J. Mol. Sci. 2008, 9, 2639-2657. doi:10.3390/ijms9122639

64. Kim, S. R.; Choi, H.; Park, J. K.; Koo, I. S.; Koh, H. J. Bull. Korean Chem. Soc. 2014, 35, 51-56. doi:10.5012/bkcs.2014.35.1.51

65. Koh, H. J.; Kang, S. J. Bull. Korean Chem. Soc. 2014, 35, 2285-2289. doi:10.5012/bkcs.2014.35.8.2285

66. Kim, Y. H.; Choi, H.; Koo, I. S.; Koh, H. J. Bull. Korean Chem. Soc. 2015, 36, 2819-2822. doi:10.1002/bkcs.10573

67. Koo, I. S.; Yang, K.; Park, J. K.; Woo, M. Y.; Cho, J. M.; Lee, J. P.; Lee, I. Bull. Korean Chem. Soc. 2005, 26, 1241-1245.

68. Koh, H.-J.; Kang, S.-J. Bull. Korean Chem. Soc. 2011, 32, 1897-1901. doi:10.5012/bkcs.2011.32.6.1897

69. Bentley, T. W.; Jones, R. O.; Kang, D. H.; Koo, I. S. J. Phys. Org. Chem. 2009, 22, 799-806. doi:10.1002/poc.1522

70. Bentley, T. W. J. Org. Chem. 2008, 73, 6251-6257. doi:10.1021/j0800841g

71. Koo, I. S.; Lee, I.; Oh, J.; Yang, K.; Bentley, T. W. J. Phys. Org. Chem. 1993, 6, 223-227. doi:10.1002/poc.610060405

72. King, J. F.; Lam, J. Y. L.; Skonieczny, S. J. Am. Chem. Soc. 1992, 114, 1743-1749. doi:10.1021/ja00031a032

73. King, J. F.; Durst, T. J. Am. Chem. Soc. 1965, 87, 5684-5692. doi:10.1021/ja00952a029

74. King, J. F. Acc. Chem. Res. 1975, 8, 10-17. doi:10.1021/ar50085a002

75. King, J. F.; Lam, J. Y. L.; Dave, V. J. Org. Chem. 1995, 60, 2831-2834. doi:10.1021/jo00114a036

76. Cafferata, L. F. R.; Desvard, O. E.; Sicre, J. E. J. Chem. Soc., Perkin Trans. 2 1981, 940-943. doi:10.1039/p29810000940

77. Thornton, E. R. Solvolysis Mechanisms; The Roland Press Company: New York, NY, USA, 1964; pp 212-226.

78. Robertson, R. E. Solvolysis in Water. In Progress in Physical Organic Chemistry; Streitwieser, A., Jr.; Taft, R. W., Eds.; John Wiley \& Sons: New York, NY, USA, 1967; Vol. 4, pp 213-280. doi:10.1002/9780470171837.ch5

79. Hammett, L. P. Physical Organic Chemistry, Reaction Rates, Equilibria, and Mechanisms, 2nd ed.; McGraw Hill: New York, NY, USA, 1970; p 130.

80. Swain, C. G.; Thornton, E. R. J. Am. Chem. Soc. 1962, 84, 822-826. doi:10.1021/ja00864a029

81. Ingold, C. K. Structure and Mechanism in Organic Chemistry, 2nd ed.; Cornell University Press: Ithaca, New York, USA, 1969; pp 427-428. 


\section{License and Terms}

This is an open access article licensed under the terms of the Beilstein-Institut Open Access License Agreement (https://www.beilstein-journals.org/bjoc/terms), which is identical to the Creative Commons Attribution 4.0 International License

(https://creativecommons.org/licenses/by/4.0). The reuse of material under this license requires that the author(s), source and license are credited. Third-party material in this article could be subject to other licenses (typically indicated in the credit line), and in this case, users are required to obtain permission from the license holder to reuse the material.

The definitive version of this article is the electronic one which can be found at:

https://doi.org/10.3762/bjoc.18.13 